\title{
The therapeutic relationship in child psychotherapy: Integrating the perspectives of children, parents and therapists
}

\begin{abstract}
This study addresses the therapeutic relationship in child psychotherapy, through an exploration of the experience of the main actors engaged in child psychotherapy. Objectives: To describe and analyse the therapeutic relationship integrating the views of children, parents and therapists. Methods: This study employs a qualitative methodology, assuming a discovery-oriented approach which draws from grounded theory. Twelve psychotherapy triads participated, composed of children aged 6 to 10, their parents and psychotherapists. Semi-structured follow-up interviews were conducted $(\mathrm{N}=36)$, including a drawing in the case of the children. Results: A positive therapeutic relationship with children and parents was viewed as a gradually constructed process, based on a positive emotional encounter between participants. It was facilitated primarily by the therapist's commitment and playful stance, the child and therapist mutual involvement, and the parent's collaboration. These aspects entailed a trustful, validating and caring relationship, that shaped children and parents' motivations towards therapy and facilitated change. Conclusions: From a multiple-perspective approach, therapy was conceived as a relational experience. The development of positive relationships required different and evolving dispositions from therapy main actors. Therapists' genuine feelings and engagement in therapeutic activity seem central, underlining the importance of addressing relational aspects in child therapy research and training.
\end{abstract}

Keywords: child therapy, therapeutic relationship, therapeutic alliance, therapeutic change, qualitative methods, multiple perspectives. 


\section{Introduction}

The relationship between patient and therapist is considered a central aspect of all psychotherapy and the quality of that relationship has proven to be one of the factors most robustly associated with therapeutic outcome in adults (Safran \& Muran, 2006). The conceptualization of the therapeutic relationship in the literature is quite diverse, as it depends on the researcher's theoretical background (Hayes, 2017; Kennedy \& Midgley, 2007). One transtheoretical definition of the therapeutic relationship is proposed by Gelso (2014) as: 'feelings and attitudes that therapists and clients experience for each other, and the way they are expressed', encompassing the real relationship, the therapeutic alliance, plus transferential and countertransferential components, organized in a tripartite model.

The relational aspects of therapy have been frequently studied within the framework of the therapeutic alliance, often drawing from Bordin's (1979) transtheoretical alliance model (Altimir et al., 2017; Wilmots et al., 2019). This model contains three interrelated dimensions: agreement in goals, in tasks, and the therapeutic bond (Bordin, 1979), and emphasizes the role of patient's conscious or rational collaboration (Safran \& Muran, 2006). The therapeutic alliance has shown to be a robust predictor of outcomes in psychotherapy with children and adolescents (Kazdin et al., 2006; Shirk \& Karver, 2011). However, the applicability of the concept of a 'therapeutic alliance' in child psychotherapy practice has been debated, as it is not clear that children are able to 'collaborate' with the therapist or 'agree on goals and tasks', as outlined within Bordin's alliance model (Elvins \& Green, 2008; Karver et al., 2006). In this sense, the concept of the therapeutic relationship provides a broader framework for the examination of the relational aspects of child psychotherapy, which is the focus of this study. 
Conceptualisations of the therapeutic encounter often share the idea of psychotherapy as a two-person relationship: patient and therapist. However, child psychotherapy contains multiple levels of relationships: at least one between child and therapist, and others among parent(s)/caregiver(s) and therapist (Gvion \& Bar, 2014; Hayes, 2017, Karver et al., 2018). These multiple relationships can be conceived as a triadic relational connection, as each relationship influences the others (Gvion \& Bar, 2014). The few studies conducted about the relationship between parents and the child's therapist have reported that the parent's degree of participation in their child's therapy is associated with outcome (DeVet et al., 2003, Karver et al., 2018). The quality of the relationship between parents and their child's therapist is linked with the parent's commitment and extra-session support, affecting the child's therapeutic change (Kazdin et al., 2006; Marker et al., 2013). A positive alliance with parents is associated with improved parental skills and family interactions (Kazdin et al., 2006), and influences the quality of the therapeutic alliance with the child (Campbell \& Simmonds, 2011; Kazdin et al., 2006). Positive alliance both with children and parents support adherence to treatment, preventing early dropouts (Hawley \& Weisz, 2005).

However, the valuation of therapeutic aspects may change according to who reports them (Accurso \& Garland, 2015; Carroll, 2002; Stith et al., 1996). In the case of research on relationships in child psychotherapy, it has been based mainly on parents' and therapists' reports (Noyce \& Simpson, 2018); children have been excluded generally as valid informers of their own psychotherapy experiences, because of the belief that they are unable to provide legitimate comments about their experiences (Gibson \& Cartwright, 2014), or that their views would be considered too superficial (Midgley et al., 2006). Yet contemporary social research frameworks criticize an adult-centred approach, advocating 
new methods that 'lift up' children's perspectives and experiences (Luttrell, 2010). Researching children's views of psychotherapy requires the development and use of innovative research methods that enable children to express themselves in a safe and ageappropriate way (Calberg et al., 2009; Midgley, 2004).

Overall, studies of children's experiences of therapy have found that children underline the therapeutic relationship as a central aspect of the therapeutic process and change (Alamo, 2019; Capella et. al., 2015; Carlberg et al., 2009; Carroll 2002; Kazdin et al., 2006; Stith et al., 1996), as children emphasized the value of a therapist who emotionally supports and listens to them (Capella et al., 2015), and in some studies suggesting that the element they liked most about therapy was simply spending time with their therapist (Carlberg et al., 2009). Despite these findings, few researchers have studied the development of the therapeutic relationship with children under 11 years old (Noyce \& Simpson, 2018). This matter is particularly relevant to Chile, considering that in this country the prevalence of psychiatric disorders in children between 4 and 11 years old is $27.8 \%$ (Vicente et al., 2016). This value is slightly higher than the $20 \%$ prevalence reported worldwide (World Health Organization, 2005), and represents a significant group that requires mental health attention.

This study focuses on middle childhood (6-11 years old) also referred to as 'school age children' (Pappalia \& Martorell, 2015), as they are a group that has received less attention in terms of research into the nature of the therapeutic process (Kennedy and Midgley, 2007). Therefore, this paper addresses the therapeutic relationship with school age children, seeking to understand how this relationship shapes, evolves and impacts the therapeutic process. The study is based on the perspectives of children, parents and therapists, as first-hand informers of their therapeutic experiences. 


\section{Methods}

This study employs a qualitative design, assuming a discovery-oriented approach which draws on grounded theory (Corbin \& Strauss, 2008).

\section{Setting}

The study reported here was part of a larger research project titled "Success and failure experiences in psychotherapy - Construction of a multidimensional comprehensive model", financed by the National Science and Technology Development Fund of the Chilean Government. This larger project was conducted in Santiago, Chile, and comprised diverse consultation groups: adults, adolescents and children with different disorders or difficulties $(\mathrm{N}=102)$. Mental health in Chile is primarily provided though outpatient public and private services, and for the larger study participation agreements were established with 6 mental health centres of public, private and university settings.

\section{Participants}

Inclusion criteria for this study were that children were between 6 and 11 years old and had attended a minimum of six therapy sessions with at least one of their parents involved in the process. Exclusion criteria was the presence of cognitive impairment in children. Seventeen children had taken part in the larger project; of them, twelve met the inclusion/exclusion criteria for this study. Fifteen parents who actively accompanied their child's therapeutic process, and nine psychotherapists were included, as two of them had more than one case, adding a total of thirty-six participants.

Each child had been referred to a child and adolescent mental health service in Chile, for a range of reasons: externalizing problems (ADD, emotional dysregulation, oppositional defiant behaviour), internalizing problems (anxious and/or depressive symptoms, social inhibition) and because of the impact of child abuse (emotional, physical 
or sexual abuse). Parents were involved in individual and joint sessions with their children. Most therapies ended with an agreed discharge but in one case the family dropped out. The therapists represented diverse clinical orientations and professional experience, including systemic, psychoanalytic and cognitive constructivist approaches. Therapeutic interventions were offered through individual and family sessions, including directive and nondirective play, art and narrative techniques. Therapies were open-ended and lasted from 1.5 to 28 months; they are described as long when they continued for more than 6 months. Table 1 includes details about participants, length and frequency of therapies.

\section{Procedure}

Participants were contacted at the beginning of psychotherapy, asking for the child's informed assent and the informed consent of parents and therapist to participate in this study. Participants were contacted within three months of therapy ending, for those who had given consent at the start of therapy. Individual semi-structured interviews were carried out with all participants in the same mental health centre where their therapy was conducted, with the exception of the drop out case which took place at the child's home. Children's interviews were supported with drawings and were led by trained child psychologists, who had not been involved with their therapies. Interviews were audio recorded, and transcribed using Mergenthaler Norms (Mergenthaler \& Gril, 1996); a total of 36 interviews were completed, comprising 3 interviews per case.

\section{Data collection method}

\section{Individual semi-structured interviews}

Individual interviews were carried out separately with the parent, child and therapist. An interview topic guide was created for the broader research project previously mentioned. It included an opening question about the global experience of the recent 
therapy, and then deepened through open-ended questions organized in six topics: diagnosis, expectations, therapeutic process, therapeutic relationship, outcome and ending process. The interview guide followed the same structure for children, parents and therapists, and was adapted for each perspective using age-appropriate language and depending on the specific roles that each participant had in psychotherapy.

Regarding the therapeutic relationship, the guiding questions for the child interview were: What did you think about your psychologist? How was he/she? How did you feel with him/her? Were there changes? How did you get along with him/her? How were your feelings towards him/her? What did you like most/least about him/her? What did you liked/disliked doing with him/her? Questions about the relationship between the therapist and the parents were also asked: Did the psychologist sometimes talk to your mom/dad? How did your mom/dad get along with him/her? How was your mom/dad with him/her?

\section{Drawings supporting children's narratives}

In addition to the interviews, children were invited to draw pictures to enable a richer understanding of their experiences of therapy. The drawing included in this study was: "My psychologist and me", developed by the first author; the interviewer requested that the child draw him/herself with their therapist during therapy. The drawing activity took place as part of the interview; interviewers engaged with children's spontaneous verbalizations about their drawings and asked questions about what they drew, such that the drawing exercise and the interview topic guide were in constant dialogue.

\section{Data analysis}

The interviews were analysed using grounded theory methods (Corbin \& Strauss, 2008), starting with open coding, based on a concept-indicator model, where emerging concepts from verbal and visual data were labelled as they related to individual events 
(indicators), and then were developed and categorized based on contextual and theoretical knowledge (Corbin \& Strauss, 2008; Titscher et. al., 2000). In addition, through an iterative process involving constant comparison, emerging concepts were categorized and organized in a hierarchical structure, and memos were written to record how concepts and categories develop and interrelate (Titscher et al., 2000). Following open coding process, axial coding of data was executed, in order to map relations between concepts and categories (Titscher et al., 2000). The coding process was supported by ATLAS.TI v7 software for qualitative data analysis.

To ensure intersubjective validation of findings, a triangulation strategy was implemented, whereby five coders participated in the analysis of qualitative data and then compared findings and sought agreement (Flick, 2018). This process seeks to reduce coder bias and enrich the coding process, as it allows several perspectives to be considered in the identification and interpretation of categories (Altimir et. al., 2017). Interviews were also grouped and analysed by case, creating a summary for each case of the most relevant aspects of the participants' narratives.

Drawings were incorporated at two stages of the analysis: first as part of overall verbal data, as children's spontaneous comments and answers related to their drawings were part of the transcription. And in a second stage, through a specific qualitative analysis method developed by some of the authors of the study (Alamo, 2019; Alamo et. al, 2018; Núñez et al., 2018) summarized in Table 2. The analysis of children's interviews and drawings were integrated through methodological triangulation (Flick, 2018).

\section{Ethical considerations}


The study was granted ethical approval from the Scientific Ethics Committee in Social Sciences, Arts and Humanities of the Pontifical Catholic University of Chile. The identity of participants has been removed to ensure confidentiality.

\section{Results}

Overall, participants described a positive therapeutic relationship between the child and the therapist, and they tended to express positive valuations of the therapeutic process. Consequently, the findings from this study are particularly illustrative of what makes a good, rather than poor, therapeutic relationship.

A positive therapeutic relationship was described by participants as a dynamic, constructed process that involved all actors, with children, therapists and parents participating in different ways (Figure 1). The therapist assumed the initial lead, encouraging the child to express freely and take ownership of the therapeutic space, and interacting with the child through a playful stance. This attitude facilitated the child's participation as it opened a positive emotional experience for the child based on play and having fun with the therapist. This interaction enabled the construction of a trusting and validating therapeutic relationship. Parents constructed a collaborative relationship as well with the therapist, as they felt the therapist was committed to their case, validated and supported them and their child, interacting with them in a kind and professional way. A positive therapeutic relationship also shaped a higher motivation towards therapy, overcoming possible initial reticence in children and parents. In longer therapies this relationship enhanced identity and relational changes in the child.

To deepen the understanding of the construction of a positive therapeutic relationship, the core features of this process are presented in detail and organized in four themes: a) a new encounter: meeting an adult who intends to help, b) a mutually involved 
encounter: having fun and playing together , c) construction of a trustful, supportive and caring relationship, d) role of the therapeutic relationship in shaping children and parents' motivations towards therapy and as a facilitator of change.

\section{a) A new encounter: meeting an adult that intends to help}

Therapists' characteristics and attitudes were described variously by participants, as children and parents often answered questions about the therapeutic process by referring to the therapist. Therapists played a leading role in inviting the child to interact, as they were viewed by participants as interested, affectionate and kind towards the child. In addition, the therapists' playful stance was described, as they connected in a way that was appropriate given the child's age and developmental stage. This description largely matched the therapists' own descriptions of their practice and how they aimed to be:

"like an adult who wants to be with her, who wants to connect with her from her own language, respecting her (...) and a very playful therapist, because as I invited her to be more childish, it made me also be quite playful and fun".

Children and parents also identified professional qualities and more personal traits of therapists than did therapists themselves, describing therapists as competent, affable, friendly and nice people, who treated them well. Parents also highlighted the willingness of therapists to do more than expected from their professional role, and some parents valued their ability to communicate information about their child in a clear way, as well as being receptive and non-judgemental.

Regarding children's disposition towards the therapeutic encounter, they were characterized as collaborative by therapists. However, children were described with a more passive role in the first sessions, which from the children's perspective related to a sense of anxiety about being alone without their parents, possible embarrassment, demotivation and 
insecurity regarding how the therapist would be, as well as concerns about the usefulness of therapy. Some therapists associated the child's passivity to over-compliance towards them. For example, one therapist described a girl in her first sessions:

"She was not a very genuine girl in the contact, a girl with a slightly frozen smile, one of those girls that when you ask in the session "what would you like to do?", they answer: "whatever you want".

According to the participants, some children initially expressed aversion to participating in therapy, through a passive attitude in those with internalizing symptoms, and difficult and confrontational attitudes towards the therapist in children with externalizing symptomatology. A therapist describes this experience as follows:

"It was a case in which initially [child's name] could not stand much being in the consultation room, he constantly went outside (...). At the beginning creating the bond was tough $(. .$.$) however, little by little this bond was established...".$

Parents were described primarily by themselves and the therapists; children were less likely to spontaneously discuss their parents. Descriptions of parents underlined their collaboration and positive disposition and were characterized as motivated and committed, seeking help because they were concerned about their child's issues. However, as was the case for the children, this positive presentation was not always the starting point. It was observed that parents experienced initial mistrust towards the therapist, and doubts about the therapist's professional skills, mainly as a result of prior negative experiences with therapists or the therapist's young age.

\section{b) A mutually involved encounter: having fun and playing together}

Playful activities were viewed by children and parents as the core interaction in therapy. Children were described as experiencing good and happy feelings when 
interacting with their therapist, and therapists also recalled positive feelings when playing with the child. Therapists' seek to validate and empower the child in the therapeutic encounter. Following the child's timings, rhythms and needs, was considered a facilitator of the relationship by therapists. In describing how they tried to be, therapists emphasized the importance of an open disposition, as this made space for the child's free expression and leading role. One mother described her daughter's experience as follows:

"She loved it [therapy], it was like her space (...) she could "do and undo" (...) and she played, and she liked it because she made different things (...) [therapist name] let her control the situation a bit, and she liked that, she had a good time, it was her time to play, to express herself, then for her it was like super important”.

As the therapist sought to connect with the child through a child-centred stance, children gradually felt that they could occupy the therapeutic space, express themselves more freely and enjoy being with the therapist. A therapist describes his stance as: "We started with free games. He brought some cards, which I think were a complete facilitator of our bond. We got on the floor, so he could teach me how to play. This interaction allowed me to get out of the expert role, of that distant role". Consequently, a more empowered attitude in the therapeutic relationship was shown by the children. One therapist describes this process as:

"He went from being tense, distrustful of the space and the things he could say or do, to lie on the floor if he wanted, or to play what he wanted, or if he didn't want to do certain things, I felt that he had the ability to express more, what was happening to him, what he felt...".

However, children usually said little about the therapeutic relationship beyond it being good. It was through their drawings that they highlighted joint activity as the core 
interaction of the therapeutic relationship, as they illustrated happy scenes with their therapists. When analysing the content of the drawing of "My psychologist and me" (Drawing 1) made during the interview by a 7-year-old girl, the central theme was a playful encounter between her and her therapist. Both figures displayed happy expressions on their faces, and flexible -ready to play- body postures, with the only distinction being the therapist's larger size. The environment was represented by a detailed doll house that occupied a central place between them. Their interaction was positive and mediated through play, in which they were mutually involved. The girl explained that they were 'playing house - and speaking like characters', referring to a pretend mode of speech. She expressed that they both felt 'good' playing in this way. The drawing is consistent with what was expressed verbally, but emphasizing symmetry in the figures position, attitude and affection, and that joint play mediates the relationship.

In the drawing of a 10-year-old boy of "My psychologist and me" (Drawing 2), the central theme was the child and the therapist drawing together. Both figures are positioned backwards as they are facing a drawing board, with the same flexible and active body postures, and the therapist is bigger. The environment was represented by the drawing board in a central position. Their interaction is positive and mediated through drawing activity, in which they are mutually involved. The boy said about his picture that he felt 'good and comfortable' when drawing with his therapist. This drawing supports what was expressed verbally, but emphasises the equal level of involvement, joint and symmetric action in the therapeutic relationship, which focuses on the child's art interests.

In both children's drawings, in addition to the expression of positive emotions, symmetric actions and involvement levels were described. In these cases children completed long-term therapies, and the mutuality with the therapist represented in their 
drawings appeared in other children's drawings who also engaged in longer-term therapies. This mutual joy of playing together was also described by parents and therapists, and it suggested a symmetrical and positive emotional encounter between child and therapist. A mother of a 10-year-old girl put it as follows:

"In the last session the psychologist made me come in before it ended and she (child) was cooking with the psychologist. She was making food, had lunch with her (psychologist), had taken coffee and I arrived, I arrived for dessert (...) it was like she felt she was with another girl, I mean, I perceived that... it was like she played, but with another girl".

In briefer therapies, positive emotions were also represented in children's drawings, but the interaction was more asymmetric, focused on the therapist's leading role and the patient's following role, where the therapist was asking something or requesting the child to do a specific task, and the child was answering or performing what was enquired.

Whereas for children and parents, playing with the therapist was valued for the positive experience in itself; different conceptualizations and experiences of the role of play were shaped by the therapist's theoretical background. In general therapists suggested that playing was a fun activity that engaged and prompted children towards therapeuticfocused work. However, playing too much with the child made some therapists feel insecure about their professional duty, as one relatively inexperienced therapist explained: “The only thing we did was play. And I felt that I wasn't doing anything, because I thought... this boy comes to play, his parents are trusting me, and I don't know if this helps him (...) I tried to put some elements into his play (...) try to put some of the therapy in (...). So, when he began to bond, I began to tell him gradually "I don't want to play war anymore, let's do something else". 


\section{c) Construction of a trustful, supportive and caring relationship}

When participants described the therapeutic relationship, the emotional quality of the encounter emerged as of primary importance; they indicated that it was a good relationship that comprised positive/happy feelings. A parent describes this relationship as:

"It was super good, he (child) liked to go. One day I told him we were going, and I saw that he got happy, and I said: "you like to go?" "Yes, I like it, because I have fun and play, we do fun things", and he also liked it because he could talk with her, then he felt good (...) He felt he could tell her anything (...) he could unburden...".

Core elements encompassed in the description of the therapeutic relationship, such as trust and affection, were built through an ongoing process as therapy developed. One therapist reflected about the construction of trust as follows:

"Trust allowed him to bring his own topics, to go from being uncomfortable, from mistrust in the space with me, to being able to communicate his issues (...) when he told me things, he opened himself to me, I did not criticize him but accepted what he was showing me...".

As a result of an interactional process between child and therapist, a stronger emotional connection emerged, as a therapist explained:

"In the beginning she arrived very over-adapted, to offer me something very correct, a correct girl (...) so we built a relationship where the main invitation was for her to be more like a child (...) to be able to express herself more freely. And when this was achieved it was a very strong relationship, in terms of atonement, complicity... a fun relationship, with lots of laughter, but also validation". Progressively the therapist was held in mind by the child and the parents, and participants described that children cared for the therapist and the therapeutic space and 
talked about their therapist when at home. In longer therapies, therapists also underlined the child's affectionate and attentive attitude towards them, which was viewed as expression of a positive bond, as one therapist explained when describing the relationship: "I felt close to him (...) in general I think that there was trust, there was affection between the two of us (...) and that speaks to the fact that we had a good bond (...) he had the capacity to be able to express more (...) and to ask me things, about my nephews for example, so there was a good bond in that sense".

In longer processes, therapists were viewed as an ally by the children, as the therapist was a supportive figure for them. This aspect was expressed by one therapist as follows: “[Child's name] bonded a lot with me, so when her mother lost control, (child`s name] told her: "I'm going to tell on you to my psychologist (...) if you treat me badly, I will tell my psychologist." Then she began to express her needs, to set limits, even to her mother, which she did not do before".

The positive relationship described also created a significant loss once therapy ended, mostly in longer therapies. Children recalled feeling sad about not being able to see their therapist anymore, expressing that they would miss their therapist and wished not to be forgotten by them. A six-year-old girl recalled the end of therapy:

"I did not want to leave (...) but I gave him something we did (...) A drawing, I came here, and I gave it to him so he wouldn't forget me".

The relationship between parents and therapists was also described as a good relationship by participants, characterized by parents and therapists as trusting, close, collaborative and supportive. A mother referred to the relationship with her daughter's therapist as: 
"A relationship of affection is created, because deep down you have to show yourself as you are, all your defects, what you do well, what you do wrong, and you have to be like an open book because if you don't, it doesn't work, then a bond is generated necessarily".

As in the therapeutic relationship with children, parents and therapists noted that parents' trust, closeness, affection and feeling supported developed over time. This process began with the parent's positive valuation of the therapist's commitment and interest towards their child. Other important elements identified by parents for the construction of a positive relationship with the therapist, included appreciation of the therapist's personal style, feeling comfortable with a therapist who listened in a receptive way and frequently helped with issues that went beyond the initial reason for consultation. Parents felt they were no longer alone with their child's difficulties, as the therapist shared a genuine concern for the child's wellbeing and wanted to help. Some parents also viewed this relationship as helpful for them, and positively valued this relationship.

\section{d) The role of the therapeutic relationship in shaping children and parents' motivation towards therapy and as a facilitator of change}

As previously described, a positive therapeutic relationship shaped children and parents' motivation and belief in therapy. Participants described that the initial reticence in children changed and they began to feel motivated to meet with the therapist. A 10-yearold boy describes this event in the following way:

“At first, I was a little nervous, we didn't know each other, and then I got used to it, we started doing more sessions (...) but at first it was like 'ajj' (in rejection tone) and I thought "I don't want to go in"; like embarrassment and fear (...). I wanted to 
be with my dad, with my mom, and then I went in and realized that the lady was nice, that it was cool to be there, we drew together, which is something I love". Parents went along with this process, as their initial reserve changed towards a positive disposition and validation towards the therapist, as they valued the therapist's attitude and approved the therapist's work. One mother recounted this experience as:

"I was scared in the first session, I mean, I saw her so young (...) and my husband felt rejection too. (...) But when I listened to her and she paid close attention to what I was saying (...) and you realize that, that she understands you, helps you, and what she is saying really helps, because when you do that, it really (...) works, so that for me was incredible".

Parents responded to the therapist's dedication with a higher engagement in their children's therapy, committing to change and compliance towards the therapist's interventions and guidelines. The construction of a positive relationship with the parents, was viewed as a facilitator of the child's therapeutic process, as one therapist noted:

"I think it influenced a lot, because if we had not formed a good bond, first they would have dropped-out long ago, and we could not have worked on certain topics (...) the fact that we had a good relationship enabled her in some sessions to highly encourage her son, she was super important, I felt she really supported his therapy". Once a positive therapeutic relationship had shaped a higher motivation of children and parents towards therapy, it facilitated the development more extensive therapies. In these cases, the therapeutic relationship was viewed as a facilitator of change in children's self-concept and relational repertoire. The therapeutic relationship worked as a relational modelling tool for the child, as one therapist explained: 
"She became conscious that those little things that happened to her with me, also happened to her with her friends. So that we could address them for her other relationships. So, they were like small misunderstandings, but they were very useful for her to realize certain aspects of how she was behaving".

Some therapists underlined that the establishment of a relationship with someone who validated the child and focused on them beyond their difficulties or problems also worked as a facilitator of change in the child, as one therapist said:

"I believe that being able to interact with him without this prejudgment that he's the bad boy (...), constructing a more positive relationship with him, with an adult that wasn't his parents or family. I think that having someone who could listen to him, who could understand him, who could play without scolding him or telling him what to do or not do, I think that helped him".

As children felt validated in the therapeutic relationship, they gained confidence in other contexts too. Children began to speak out their needs and feelings and strengthened their social skills. One boy described the therapist's help in the following way:

"She helped me with my attitude, with my person, with myself, because before I was more fearful, I was shyer, I couldn't make friends, I only had two, and after I had more (...). And the therapy helped me because it helped me to find the confidence I needed to talk to other people".

Concerning parents, they appreciated that they were included in their child's therapy process, and reported that they also felt like patients in the relationship with their child's therapist. As therapist and parents established collaborative work, it facilitated that parents overcome their sense of ineffectiveness and insecurity, as they managed to deal with problematic issues with the therapist's help. 


\section{Discussion}

According to the perspectives of the main actors involved in this study, child psychotherapy was viewed as a relational experience, particularly by children and parents, who made no real distinction between therapeutic interventions and interactions. This coincides with Gelso's (2019) position, who argues that techniques and relationship are not separate entities, as their expression interrelates through the therapeutic process. In this sense, the use of play and playful activities as central therapeutic techniques in child psychotherapy, acquired a higher importance through their relational value in this study, as they facilitated a positive relationship between patient and therapist. This finding opens up a discussion about the role of play in child psychotherapy, as it extends its use beyond the technical dimension encompassed in each therapist's theoretical background, drawing attention to children's experience of play as part of the therapeutic encounter. How the therapist interacts during playful activities seemed central in this study, as the therapist's full engagement made it possible for the child and therapist to experience mutual involvement. This element emphasizes the role of the therapist's genuineness, broadly defined as the use of the real self and sincere behaviour in the therapeutic relationship. Gelso (2019) underlines the fundamental value of the real relationship in the psychotherapy relationship, considering genuineness as one of its basic qualities. The role of genuineness has been previously discussed in child-centred play therapy as a central aspect of the process (Blanco et al., 2014).

Concerning the formation and development of the therapeutic relationship, initial reticence among children and their parents towards the therapist and therapy were observed; similar findings have been reported in previous studies (Elvins \& Green, 2008; Karver et al., 2006; Shirk \& Karver, 2011). However, as the therapeutic relationship was 
positively experienced by both children and parents, their motivation towards therapy increased, enhancing adherence to therapy (Hawley \& Weisz, 2005; Karver et al., 2018). In this study, an improved relationship stemmed initially from the therapist's attitude and disposition. Similar features have been described as the therapist offeredGelso (2019) has described this as the features that work as facilitative conditions of therapeutic change, but do not represent the whole relational dimension as they focus solely on the therapist's contribution.

Accordingly, the therapeutic relationship was viewed as a gradually co-constructed process, in which therapists, children and parents assumed different roles as the relationship developed. This finding underlines the conceptualization of the therapeutic relationship as a dynamic process (Safran, \& Muran, 2006), which requires time to develop. In long-term therapies, particular affective phenomena were observed, such as the internalization of the therapist as a significant other and as an ally for the child. The advocacy role of the therapist has been previously described (Caroll, 2002), and seems particularly relevant when children require higher regulation. The internalization of the therapist as a positive figure for the child recalls elements of Attachment Theory; a core contention of this theory is that the therapist can undertake the role of an attachment figure within the relationship, and when this relationship favours affective bonding it can become part of the child's internalized relational resources (Holmes, 2015).

Regarding the therapy ending process, many children experienced mixed feelings as they missed their therapist once therapy had concluded. This result has been previously described, as patients often find it difficult to end the therapeutic relationship, involving loss and a mourning process for the child (Karush, 2014). This finding highlights the notion that the ending of psychotherapy occupies a significant place in the overall 
therapeutic experience for children, and that the associated feelings accompany them after the process concludes.

As in previous studies (Accurso \& Garland, 2015; DeVet et al., 2003; Hawley \& Weisz, 2005) a positive relationship between parents and therapists strengthened a cooperative role of parents in the child's therapy and represented a supportive relationship for parents. In addition, the child's relationship with the therapist mediated the relationship between child and parents, regulating their interaction in several ways. The triadic link in the therapeutic relationship between child-therapist-parent observed in this study has been formulated previously (Gvion \& Bar, 2014) and has significant implications for child psychotherapy process and outcome (Karver et al., 2018).

In light of the present study, the definition of the therapeutic relationship acquires particular facets in relation to child psychotherapy: the inclusion of parents/caregivers in a triadic relationship, the formative role of the relationship and the significance of the real relationship. Therefore the contributions of children, therapists and parents interrelate in a complex way as the therapeutic relationship develops.

\section{Strengths and Limitations}

There are a number of strengths to this study. The inclusion of children as participants in this study made it possible to explore a perspective which is often absent in the literature. In addition, examining various perspectives led to complex and rich findings, where participants tended to converge in a positive valuation of the therapeutic relationship (as in Zorzella et al., 2017), but at the same time differed about central aspects of the relationship Accurso \& Garland, 2015; Kazdin et al., 2006; Zandber et al., 2015). The combination of interviews and drawings worked as complementary sources of information, 
and drawings allowed children's narratives to expand, and new dimensions to appear. The inclusion of age-appropriate methods enabled children as informers on their own experience, providing rich information about child psychotherapy, as demonstrated in other studies (Capella et al., 2015; Carlberg et al., 2009; Carroll, 2002; Luttrell, 2010; Midgley, 2004).

A limitation of this study was that only positive therapeutic relationships were described. This issue is not always what happens in therapy, as sometimes a poor therapeutic relationship is experienced, compromising the therapeutic outcome (Creed \& Kendal, 2005). The overall positive views in this study may reflect a bias in the selection of participants, as almost all cases continued therapy until discharge was agreed. Only one case dropped out of therapy, in which a weaker relationship between parent and therapist was observed and the parent decided to prematurely end the therapy, as has been observed in previous studies (Hawley \& Weiss, 2005). The timing of assessment soon after the end of therapy may have influenced participants to recall more positive than negative aspects of the recent therapeutic experience, as they possibly merge the quality of the relationship with the therapeutic outcomes (Horvath et al., 2011).

\section{Implications for Practice}

The findings of this study suggest that, therapists need to pay special attention to enhance children and parents' validation and empowered role in the therapeutic relationship, and overcome possible implicit or explicit reticence. In this study, an improved initial relationship was facilitated through a triad of key elements displayed by therapists: a committed and engaged attitude, a kind and playful stance towards the child and professional capability. Attention towards these broad elements of the therapists' contribution should be underscored in practice and training (Shirk \& Russell, 1996). 
A second implication of this study for practice is that the development of play and child-centred activity are vital elements for the construction of a meaningful therapeutic relationship. This requires therapists' genuineness and true engagement. Joint play goes beyond being a technique for elaboration of psychological contents, or a facilitator for the child's collaboration; it stands out as a relational setting that enables the development of a real relationship. This idea converges with prior critiques towards therapists' training, which focuses more on developing skills and techniques than on genuineness (Blanco et al., 2014). The need to address this aspect in training and practice of child therapists is supported by this study.

A third significant element is the importance of constructing a positive therapeutic relationship both with children and parents. This issue represents a higher demand for clinicians, as two parallel and connected relationships must develop. It implies the necessity to note and address the emotional impact for therapists of bearing this dual relational demand.

Finally, attending to the ending of therapy, including a consideration of the child's specific needs to gradually move away from the therapeutic relationship, is required for good clinical practice (Novick \& Novick, 2006). In child psychotherapy, a satisfactory ending seems crucial, ensuring that children have full comprehension and active participation in this stage of the process.

\section{Implications for Research}

A multiple perspective approach towards the therapeutic relationship in child psychotherapy seems important for a more accurate grasp of its nature. In addition, measures at different moments of therapy are relevant for understanding its development. To move forward in this path, mixed method and longitudinal designs may provide broader 
and deeper information. The use of drawing as part of such studies, especially when including younger children, may also be important, for example to examine attachment relationships (Fury et al., 1997). Where possible, studies should include participants with more negative experiences of the therapeutic relationship, as well as therapies where the ending of treatment has been premature (e.g. O’Keeffe et al., 2019).

\section{References}

Accurso, E., \& Garland, A. (2015). Child, caregiver, and therapist perspectives on therapeutic alliance in usual care child psychotherapy. Psychological Assessment, 27(1), 347-352. https://doi.org/10.1037/pas0000031

Alamo, N. (2019). Contenidos y evolución del cambio en la psicoterapia con niños y niñas: Propuesta de un modelo genérico y de proceso [Contents and evolution of change in psychotherapy with boys and girls: Proposal for a generic and process model] [Doctoral dissertation, Pontifical Catholic University of Chile]. Pontifical Catholic University of Chile Repository. https://repositorio.uc.cl/handle/11534/22501

Alamo, N., Capella, C., Núñez, L, Krause, M. (2018, August 24-26). ¿Qué es lo que cambia en la psicoterapia infantil? Una aproximación cualitativa desde la mirada y la voz de los niños/as [What changes in child psychotherapy? A qualitative approach from the view and voice of children] [Paper Presentation]. Society for Psychotherapy Research -Latin American Chapter 13th Meeting, Reñaca, Chile.

Altimir, C., Capella, C., Núñez, L., Abarzúa, M., \& Krause M. (2017). Meeting in difference: Revisiting the therapeutic relationship based on patients' and therapists' experiences in several clinical contexts. J. Clin. Psychol., 73, 1510-1522. https://doi.org/10.1002/jclp.22525 
Blanco, P., Muro, J., \& Stickley, V. (2014) Understanding the Concept of Genuineness in Play Therapy: Implications for the Supervision and Teaching of Beginning Play Therapists. International Journal of Play Therapy 23(1), 44-54. https://doi.org/10.1037/a0035478

Bordin, E. S. (1979). The generalizability of the psychoanalytic concept of the working alliance. Psychotherapy, 16, 252-260. https://doi.org/10.1037/h0085885

Calberg, G., Thorén, A., Billström, S., \& Odhammar, F. (2009). Children's expectations and experiences of psychodynamic child psychotherapy. Journal of Child Psychotherapy, 35(2), 175-193. https://doi.org/10.1080/00754170902996130

Campbell, A. F., \& Simmonds, J. G. (2011). Therapist perspectives on the therapeutic alliance with children and adolescents. Counselling Psychology Quarterly, 24(3), 195-209. https://doi.org/10.1080/09515070.2011.620734

Capella, C., Rodriguez, L., Aguila, D., Dussert, D., Lama, X., Gutierrez, C., \& Beiza, G. (2015). Storied images of psychotherapeutic change: Approaching children's voices through drawings. Research in Psychotherapy: Psychopathology, Process and Outcome, 18(2), 141-151. https://doi.org/10.4081/ripppo.2015.188

Carroll, J. (2002). Play therapy: the children's views. Child and Family Social Work, 7, 177-187. https://doi.org/10.1046/j.1365-2206.2002.00234.X

Corbin, J., \& Strauss, A. (2008). Basics of qualitative research: Techniques and procedures for developing grounded theory (3rd ed.). https://doi.org/10.4135/9781452230153

Creed. T., \& Kendall, P. (2005). Therapist Alliance-Building Behavior Within a Cognitive-Behavioral Treatment for Anxiety in Youth. Journal of Consulting and Clinical Psychology, 73(3), 498-505. https://doi.org/10.1037/0022-006X.73.3.498 
DeVet, K., Kim, Y., Charlot-Swilley, D., \& Ireys, H. (2003). The Therapeutic Relationship in Child Therapy: Perspectives of Children and Mothers. Journal of Clinical Child \& Adolescent Psychology, 32(2), 277-283. https://doi.org/10.1207/S15374424JCCP3202 13

Elvins, R., \& Green, J. (2008). The conceptualization and measurement of therapeutic alliance: An empirical review. Clinical Psychology Review, 28, 1167-1187. https://doi.org/10.1016/j.cpr.2008.04.002

Flick, U. (2018). An introduction to qualitative research (6th Ed.). SAGE publications Ltd. Fury, G., Carlson, E., \& Sroufe, L. (1997). Children's Representations of Attachment Relationships in Family Drawings. Child Development, 68(6), 1154-1164. https://doi.org/10.1111/j.1467-8624.1997.tb01991.x

Gelso, C. (2019). The Therapeutic Relationship in Psychotherapy Practice. An Integrative Perspective. Routledge.

Gelso, C. (2014). A tripartite model of the therapeutic relationship: Theory, research, and practice. J. Psychotherapy Research, 24, 117-131. https://doi.org/10.1080/10503307.2013.845920

Gibson., K., \& Cartwright, C. (2014). Young clients' narratives of the purpose and outcome of counselling. British Journal of Guidance \& Counselling, 42(5), 511524. https://doi.org/10.1080/03069885.2014.925084

Gvion, Y., \& Bar, N. (2014). Sliding doors: some reflections on the parent-child-therapist triangle in parent work-child psychotherapy. Journal of Child Psychotherapy, 40(1), 58-72. https://doi.org/10.1080/0075417X.2014.883138

Harrison, L.G, Clarke, L., \& Ungerer, J.A. (2007). Children's drawings provide a new perspective on teacher-child relationship quality and school adjustment. Early 
Childhood Research Quarterly 22, 55-71.

https://doi.org/10.1016/j.ecresq.2006.10.003

Hawley, K. M., \& Weisz, J. R. (2005). Youth versus parent working alliance in usual clinical care: Distinctive associations with retention, satisfaction, and treatment outcome. Journal of Clinical Child and Adolescent Psychology, 34(1), 117- 128. https://doi.org/10.1207/s15374424jccp3401_11

Hayes, J. (2017). What leads to change? I. Common factors in child therapy. In N. Midgley, J. Hayes., \& M. Cooper (Eds.), Essential research findings in child and adolescent counselling and psychotherapy (pp. 119-147). SAGE publications Ltd.

Holmes, J. (2015). Attachment theory in clinical practice: a personal account. British Journal of Psychotherapy, 31(2), 208-228. https://doi.org/10.1111/bjp.12151

Horvath, A., Del Re, AC., Flükiger, C., \& Symonds, D. (2011). Alliance in Individual Therapy. In Norcross, J. (Ed.), Therapeutic relationships that work: EvidenceBased Responsiveness (pp. 25-69). Oxford University Press.

Karush, R. (2014). Postscripts: Reflections on the post-termination phase. The Psychoanalytic Study of the Child, 68, 234-247. https://doi.org/10.1080/00797308.2015.11785516

Karver, M. S., Handelsman, J. B., Fields, S., \& Bickman, L. (2006). Meta-analysis of therapeutic relationship variables in youth and family therapy: The evidence for different relationship variables in the child and adolescent treatment outcome literature. Clinical psychology review, 26(1), 50-65. https://doi.org/10.1016/j.cpr.2005.09.001

Karver, M.S., Monahan, M., De Nadai, A.S., \& Shirk, S.R. (2018). Meta-Analysis of the Prospective Relation Between Alliance and Outcome in Child and Adolescent 
Psychotherapy. Psychotherapy, 55(4), 341-355. http://dx.doi.org/10.1037/pst0000176

Kazdin, A. E., Whitley, M., \& Marciano, P. L. (2006). Child-therapist and parent-therapist alliance and therapeutic change in a treatment referred for oppositional, aggressive, and antisocial behaviour. Journal of Child Psychology and Psychiatry, 47(5), 436445. https://doi.org/10.1111/j.1469-7610.2005.01475.x

Kennedy, E. \& Midgley, N. (2007). Process and Outcome Research in Child, Adolescent and Parent-Infant Psychotherapy: A Thematic Review. North Central London Strategic Health Authority.

Luttrell, W. (2010). 'A camera is a big responsibility': a lens for analyzing children's visual voices, Visual Studies, 25(3), 224-237. https://doi.org/10.1080/1472586X.2010.523274

Marker, C., Comer, J., Abramova, V., \& Kendall, P. (2013). The reciprocal relationship between alliance and symptom improvement across treatment of childhood anxiety. Journal of Clinical Child \& Adolescent Psychology, 42(1), 22-33. https://doi.org/10.1080/15374416.2012.723261

Mergenthaler, E., \& Gril, S (1996). Descripción de las reglas para la transcripción de sesiones de psicoterapia. Revista Argentina de Clínica Psicológica 5(2),163-176.

Midgley, N. (2004). Sailing between Scylla and Charybdis: Incorporating qualitative approaches into child psychotherapy research. Journal of Child Psychotherapy, 30:1, 89-111, https://doi.org/10.1080/0075417042000205814

Midgley, N., Target, M. \& Smith, J. (2006). The outcome of child psychoanalysis from the patient's point of view: A qualitative analysis of a long-term follow-up study. Psychology and Psychotherapy: Theory, Research and Practice, 79, 257-269. 
https://doi.org/10.1348/147608305X52694

Novick, J., \& Novick, K. (2006). Good Goodbyes: Knowing how to End in Psychotherapy and Psychoanalysis. Jason Aronson Inc. Publishers.

Noyce, R., \& Simpson, J. (2018). The experience of forming a therapeutic relationship from the client's perspective. Psychotherapy Research, 28(1-2), 281-296. https://doi.org710.1080/1050337.2016.1208373

Núñez, L., Alamo, N., Capella, C., \& Krause, M. (2018, August 24-26). Dibujando la relación terapéutica: relevando la experiencia subjetiva de niños y niñas en psicoterapia desde sus propias narrativas [Drawing the therapeutic relationship: highlighting the subjective experience of boys and girls in psychotherapy from their own narratives] [Paper Presentation]. Society for Psychotherapy Research -Latin American Chapter 13th Meeting, Reñaca, Chile.

O'Keeffe, S., Martin, P., Target, M. \& Midgley, N. (2019). 'I just stopped going': A mixed methods investigation into types of therapy dropout in adolescents with depression. Frontiers in Psychology. https://doi.org/10.3389/fpsyg.2019.00075

Papalia D. E., \& Martorell, G. (2015). Experience Human Development (13th Ed.). McGraw-Hill Education.

Safran, J., \& Muran, J. (2006). Has the concept of the therapeutic alliance outlived its usefulness? Psychotherapy: Theory, Research, Practice, Training, 43(3), 286-291. https://doi.org/10.1037/0033-3204.43.3.286

Shirk, S.R., \& Karver, M. (2011). Alliance in child and adolescent psychotherapy. In Norcross, J. (Ed.), Therapeutic relationships that work: Evidence-Based Responsiveness (pp. 70-91). Oxford University Press. 
Shirk, S.R., \& Russell, R.L. (1996). Change processes in child psychotherapy: revitalizing treatment and research. The Guildford Press.

Stith, S., Rosen, K., McCollum, E., Coleman, J., \& Herman, S. (1996). The voices of children: Preadolescent children's experiences in family therapy. Journal of Marital and Family Therapy, 22(1), 69-86. https://doi.org/10.1111/j.17520606.1996.tb00188.x

Titscher, M., Meyer, M., Wodak, R., \& Vetter, E. (2000). Methods of Text and Discourse Analysis: In Search of Meaning. SAGE Publications Ltd.

Vicente, B., Saldivia, S., \& Pihán, R. (2016). Prevalencias y brechas hoy; salud mental mañana. [Prevalence and gaps today; mental health tomorrow]. Acta Bioethica 22(1), 51-61. http://dx.doi.org/10.4067/S1726-569X2016000100006

World Health Organization (2005). Atlas: child and adolescent mental health resources: global concerns, implications for the future. WHO Library. https://apps.who.int/iris/bitstream/handle/10665/43307/9241563044_eng.pdf?seque $\underline{\text { nce }=1 \& \text { is Allowed }=\mathrm{y}}$

Wilmots, E., Midgley, N., Thackeray, L., Reynolds, S., \& Loades, M. (2019). The therapeutic relationship in Cognitive Behavior Therapy with depressed adolescents: A qualitative study of good-outcome cases. Psychology and Psychotherapy: Theory, Research and Practice, 1-16. https://doi.org/10.1111/papt.12232

Zandberg, L. J., Skriner, L. C., \& Chu, B. C. (2015). Client-therapist alliance discrepancies and outcome in cognitive-behavioral therapy for youth anxiety. Journal Clinical Psychology, 71(4), 313-322. https://doi.org.pucdechile.idm.oclc.org/10.1002/jclp.22167

Zorzella, K., Rependa, S., Muller. R. (2017). Therapeutic alliance over the course of child 
trauma therapy from three different perspectives. Child Abuse \& Neglect, 67, 147156. http://dx.doi.org/10.1016/j.chiabu.2017.02.032 


\section{Table 1}

Participants Demographic and Clinical Characteristics

\begin{tabular}{|c|c|c|c|c|c|c|c|c|c|c|c|}
\hline & \multicolumn{3}{|c|}{ Child } & \multicolumn{2}{|r|}{ Parent } & \multicolumn{4}{|c|}{ Therapist } & \multicolumn{2}{|c|}{ Therapy } \\
\hline & Sex & Age & $\begin{array}{c}\text { Consulting } \\
\text { reason }\end{array}$ & Age & $\begin{array}{l}\text { Relationship } \\
\text { with child }\end{array}$ & $\operatorname{Sex}$ & Age & $\begin{array}{l}\text { Theoretical } \\
\text { framework }\end{array}$ & $\begin{array}{c}\text { Practice } \\
\text { (Years) }\end{array}$ & $\begin{array}{c}\text { Extent } \\
\text { (Months) }\end{array}$ & $\begin{array}{c}\text { Sessions } \\
(N)\end{array}$ \\
\hline 1 & $\mathrm{M}$ & 8 & Physical abuse & 38 & Mother & $\mathrm{F}$ & 28 & Systemic & 4 & 24 & 55 \\
\hline 2 & $\mathrm{M}$ & 7 & ADD & 28 & Mother & $\mathrm{M}$ & 26 & $\begin{array}{c}\text { Cognitive } \\
\text { constructivist }\end{array}$ & 1 & 2.5 & 10 \\
\hline 3 & $\mathrm{M}$ & 8 & $\begin{array}{c}\text { Emotional } \\
\text { dysregulation }\end{array}$ & 39 & Mother & $\mathrm{F}$ & 28 & Systemic & 5 & 11 & 26 \\
\hline 4 & $\mathrm{~F}$ & 6 & $\begin{array}{c}\text { Emotional } \\
\text { dysregulation }\end{array}$ & 29 & Mother/father & M & 26 & $\begin{array}{c}\text { Cognitive } \\
\text { constructivist }\end{array}$ & 1 & 12 & 38 \\
\hline 5 & $\mathrm{~F}$ & 7 & Anxiety & 51 & Mother & $\mathrm{F}$ & 28 & Systemic & 5 & 13 & 24 \\
\hline 6 & $\mathrm{~F}$ & 8 & $\begin{array}{l}\text { Emotional } \\
\text { abuse }\end{array}$ & 41 & Mother & $\mathrm{F}$ & 39 & Psychoanalytic & 15 & 28 & 75 \\
\hline 7 & M & 10 & $\begin{array}{c}\text { Anxiety and } \\
\text { depression }\end{array}$ & 29 & Mother & $\mathrm{F}$ & 22 & Systemic & 1 & 26 & 45 \\
\hline 8 & $\mathrm{~F}$ & 10 & $\begin{array}{c}\text { Defiant } \\
\text { oppositional } \\
\text { behaviour }\end{array}$ & 35 & Mother & $\mathrm{F}$ & 24 & Psychoanalytic & 1.5 & 14 & 42 \\
\hline 9 & $\mathrm{M}$ & 8 & $\begin{array}{c}\text { ADD, defiant } \\
\text { oppositional } \\
\text { behaviour }\end{array}$ & 39 & Mother & $\mathrm{F}$ & 27 & $\begin{array}{c}\text { Cognitive } \\
\text { constructivist }\end{array}$ & 1 & 15 & 37 \\
\hline 10 & $\mathrm{~F}$ & 10 & Sexual abuse & $\mathrm{N} / \mathrm{I}$ & Mother/father & $\mathrm{F}$ & 32 & Psychoanalytic & 8 & 3 & 10 \\
\hline 11 & $\mathrm{M}$ & 10 & $\begin{array}{l}\text { Anxiety and } \\
\text { depression }\end{array}$ & 47 & Mother & M & 26 & $\begin{array}{c}\text { Cognitive } \\
\text { constructivist }\end{array}$ & 1 & 1.5 & 6 \\
\hline 12 & M & 8 & $\begin{array}{c}\text { Social } \\
\text { inhibition }\end{array}$ & 37 & Father & $\mathrm{F}$ & 28 & Systemic & 5 & 7 & 17 \\
\hline
\end{tabular}




\section{Table 2}

Qualitative Analysis Guidelines for Therapeutic Process-Outcome Drawings*

\begin{tabular}{|c|c|c|}
\hline & Steps of analysis & Elements of analysis \\
\hline 1. & $\begin{array}{l}\text { Context of the } \\
\text { drawing }\end{array}$ & $\begin{array}{l}\text { - What does the drawing respond to (instruction)? } \\
\text { - When was the drawing done (temporality)? } \\
\text { - Where was the drawing done (context)? }\end{array}$ \\
\hline 2. & $\begin{array}{l}\text { Content of the } \\
\text { drawing }\end{array}$ & $\begin{array}{l}\text { - Central theme/Gestalt: What does the drawing convey, } \\
\text { narrate or represent in its totality? } \\
\text { - Central figure(s): Perception or representation of oneself } \\
\text { and others in the drawing. } \\
\text { - Environment: Perception or representation of the } \\
\text { environment/context in the drawing. } \\
\text { Interaction: Relationship between the graphic elements } \\
\text { - } \text { represented (between figures and with environment). }\end{array}$ \\
\hline 3. & $\begin{array}{l}\text { Verbal narrative } \\
\text { developed through } \\
\text { the drawing }\end{array}$ & $\begin{array}{l}\text { - Child's spontaneous narration and responses to open } \\
\text { questions about the drawing }\end{array}$ \\
\hline 4. & $\begin{array}{l}\text { What does it } \\
\text { express beyond } \\
\text { verbal narrative? }\end{array}$ & $\begin{array}{l}\text { - Does the drawing add new elements to what the child said } \\
\text { verbally? What does it contribute? }\end{array}$ \\
\hline
\end{tabular}

*(Alamo, 2019; Alamo et al., 2018; Núñez et al., 2018) 


\section{Figure 1}

\section{Construction of a positive therapeutic relationship}

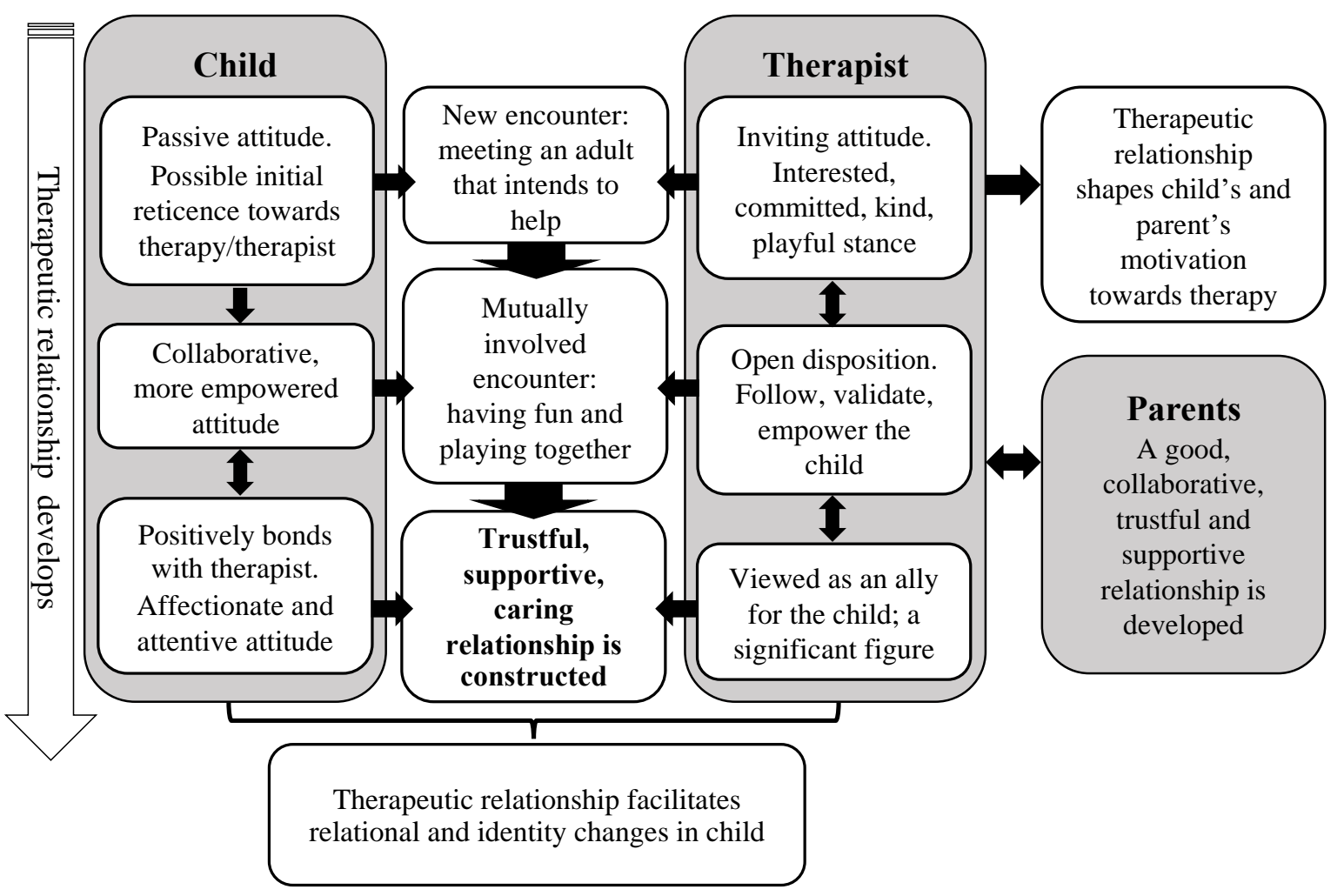




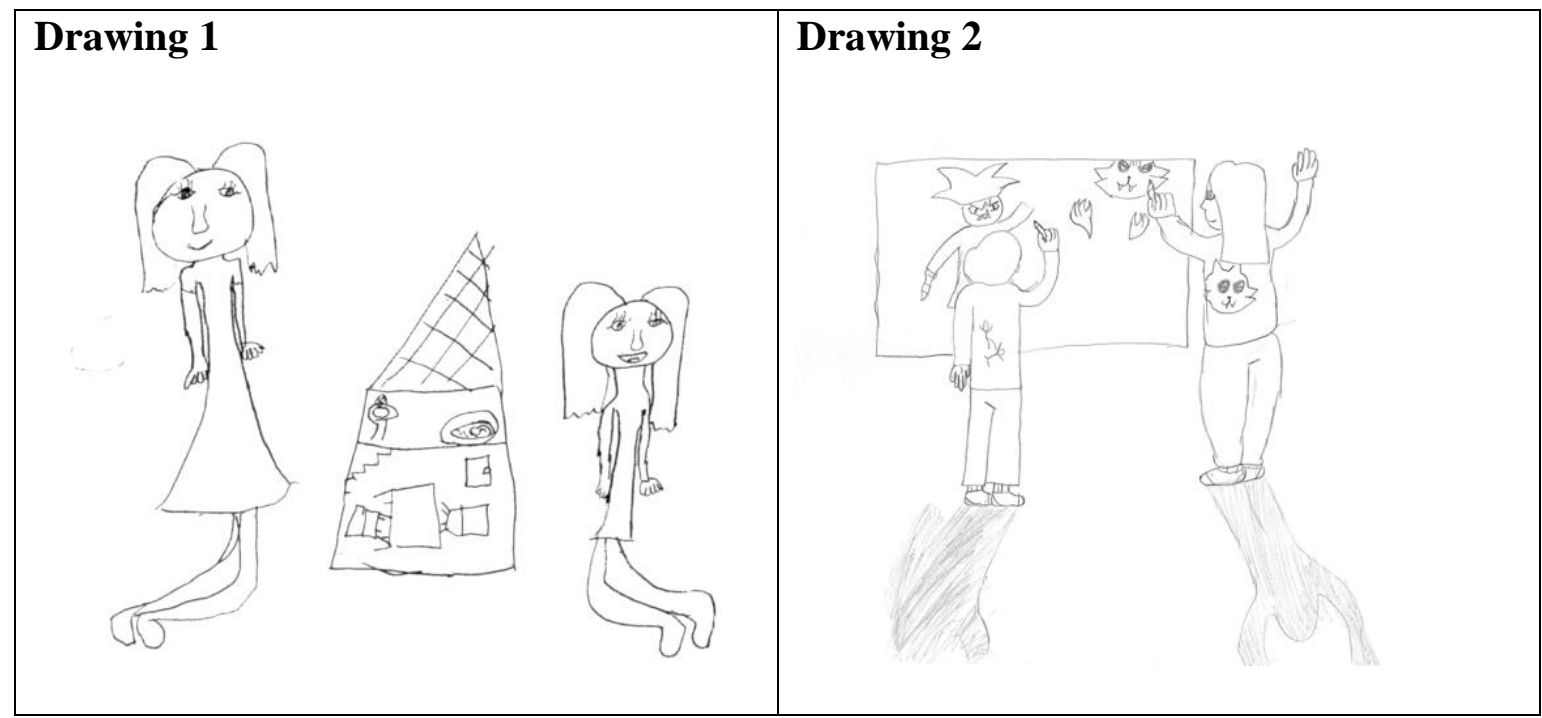

*Note: if possible, please locate drawing side by side. 